\title{
El modo de ser cínico de los dirigentes
}

\author{
THE WAY OF BEING CYNICAL OF THE LEADERS
}

Álvaro Zapata Domínguez ${ }^{1}$

\section{ReSUMEN}

Bédard $(1995,2002)$, ha identificado tres modos de ser que ella designa como "Modo de Ser mítico", "Modo de Ser sistemático", "Modo de Ser pragmático", un cuarto modo de Ser, el "Modo de Ser relacional" ha sido propuesto por Alain Chanlat (1995). Estos modos de Ser, son para los autores, la manifestación de las grandes tendencias del pensamiento occidental. En este contexto en el presente artículo se desarrolla el "Modo de Ser Cínico" de los dirigentes. Los valores fundamentales que distinguen el cinismo, son: la resistencia, la impasibilidad, la maldad.

Palabras Clave: Modos de Ser-Cinismo - Modo de Ser Cínico - Dirigentes.

\section{ABSTRACT}

Bédard $(1995,2002)$, has identified three manners of being, that she designates as the "Way of being mythical", the "Way of being systematic", and the "Way of being pragmatic". A fourth way of being, the "Way of being relational" has been proposed by Alain Chanlat (1995). These ways of being, are for the authors, the manifestation of big trends in Western thought. In this context, in the present article, the "Way of being cynical" of the leaders is developed. The fundamental values that distinguish the cynicism are: resistance, impassivity and evil.

Key words: Manners of Being, cynicism, Way of Being cynical, leaders.

Ph.D. (Management) HEC-Montreal, Profesor Titular Universidad del Valle. 
Bédard (1995, 2002), pudo observar en los dirigentes y el personal que ella analizó en su trabajo de investigación, la existencia de actitudes profundamente diferentes, pero todas ellas evolucionadas, legítimas y eficaces. En efecto, Bédard (1995) señala que:

\footnotetext{
"las tensiones, las diferencias de puntos de vista entre dirigentes, incluso los fracasos de un dirigente, a primera vista se deben a sus prácticas; pero éstas últimas contienen dos dimensiones ocultas: la idea que los dirigentes se hacen de aquello que es verdadero y su jerarquía personal de valores"
}

Buscando profundizar sobre estas dos dimensiones descubrió "que la clave se encontraba no en la ciencia sino en la filosofía, en particular en la praxeología, la epistemología, y la axiología". Sus fundamentos y aquello que los une, dice Bédard, "es la rama más clásica de la filosofía, aquella que se interroga sobre la naturaleza del Ser y de la identidad, es decir, la ontología".

\section{EL “Rombo" FiLosófico}

Analizando repetidamente las diferentes maneras de operar y manipular los marcos de análisis que cada persona utilizaba, fue surgiendo progresivamente un cuadro integrado por cuatro partes solidarias y jerarquizadas, que ella presenta bajo la forma de un rombo: las prácticas y las conductas; el proceso del pensamiento; los valores; los principios teóricos. La articulación de las cuatro dimensiones anteriores constituye la estructura profunda de lo que ella denomina un "Modo de Ser". La Gráfica siguiente presenta el denominado "rombo" filosófico.

Las prácticas. La experiencia de la realidad comienza con aquello que es perceptible a los sentidos. En el campo de la gestión como en cualquier actividad humana, lo que puede ser observado y captado por el espíritu es, en primer lugar, la manera como una persona de experiencia se conduce concretamente en el ejercicio de su actividad. Esto nos remite a la praxeología que, en el esquema propuesto por Bédard (1995, 2000), comprende la conducta y la acción, la creación, la producción y la fabricación de una obra, un bien o un servicio, así como el conjunto de los elementos que intervienen en la actividad (el sujeto creador y sus habilidades, el objeto a crear, la herramienta, la técnica y los procedimientos.

Los criterios de validez. Toda actividad es el resultado de la manera de abordar un asunto, de estudiar un problema, de tratar una problemática, de formular un objeto. La epistemología suministra los elementos que permiten hacer progresar una práctica, sometiéndola a un examen sistemático y una rectificación metódica permanente. Responde a la actitud profundamente humana que consiste, sino en buscar la verdad, al menos tratar de evitar el error. La epistemología ejerce una función crítica. Según Bédard (1995, 1999), su rol de vigilancia abarca tres objetos: el proceso o los procedimientos utilizados para realizar la actividad de producción. Esta función de validación considera el método, las normas, las reglas, los modos y los procedimientos de producción, pero no los resultados. El proceso de teorización y los fundamentos metodológicos del marco de referencia teórico que apoya la actividad de producción. La epistemología garantiza la validez del marco conceptual y las condiciones que anteceden a su formación.

Los valores fundamentales. Ninguna actividad está exenta de valores, conscientes o no. Mientras que la validación de las actividades desde el punto de vista formal está asegurada por la epistemología, su legitimidad moral viene de la axiología. En el esquema de Bédard (1995, 2000), la axiología designa el dominio general de los valores o de los preceptos, involucrando la ética, la moral y los sistemas de creencias. La axiología es definida como aquella parte de la filosofía "práctica" que tiene por objeto los principios de la "lógica del corazón y de la emoción", "una especie de metafísica de la sensibilidad y del deseo".

Los principios fundadores. La ontología es el campo del conocimiento que trata sobre las hipótesis fundamentales relacionadas con lo real y el conjunto de los seres, los principios y las teorías de la realidad. Trata del fundamento del orden de las cosas, es decir, de los principios generales de la realidad y de la inteligibilidad. Según Bédard (1995, 1999), los principios son a la ontología lo que los valores son a la axiología. Según, que trate sobre el ser humano, el universo natural o el divino, la ontología se divide en psicología, cosmología y teología. Ella constituye 
la piedra angular sobre la cual reposan la axiología, la epistemología y la praxeología.

Algunas conclusiones se desprenden del esquema de las dimensiones filosóficas. Bédard (1995, 2000), señala entre otras las siguientes: las cuatro dimensiones no son entidades separadas, sino aspectos particulares de una sola y única realidad (Bédard, 1995). Es decir, los cuatro puntos de vista filosóficos permiten aprehender el hecho social total. Si bien las cuatro partes están estrechamente relacionadas, es la ontología la que fundamenta y condiciona las otras tres; contrario a la tradición que se tiene en historia del pensamiento, en donde se señala que la primacía de la epistemología caracteriza el pensamiento filosófico, y la ontología el pensamiento científico. La epistemología y la axiología ejercen, cada una a su manera, una función de vigilancia. Las cuatro dimensiones están íntimamente articuladas y son convergentes. Cada instancia está condicionada por la presencia de las otras. La interacción díaléctica de las cuatro partes produce una práctica armoniosa, mientras que una divergencia o un desacuerdo desencadenan dificultades de funcionamiento. Cualquiera que sea la actividad humana, es la praxeología la que justifica la existencia de la función administrativa. La razón de ser de ésta es favorecer la acción recíproca de las cuatro dimensiones y de propiciar que los administradores encuentren las condiciones favorables que les permitan ejercer plenamente todas sus competencias.

\section{LOS MODOS DE SER DE LOS DIRIGENTES}

Bédard (1995, 2002), ha identificado tres modos de ser que ella designa como "Modo de Ser mítico", "Modo de Ser sistemático", "Modo de Ser pragmático", un cuarto modo de Ser, el "Modo de Ser relacional" ha sido propuesto por Alain Chanlat (1995). Estos modos de Ser, son para los autores, la manifestación de las grandes tendencias del pensamiento occidental.

La Tabla siguiente resume las categorías de cada modo ser según las dimensiones filosóficas. En nuestros estudios etnográficos pudimos constatar la presencia de los cuatro modos de ser en el comportamiento de los dirigentes de las empresas estudiadas. El análisis que se presenta más adelante recoge una síntesis de las tales observaciones.

TABLA 1 / Modos de ser y dimensiones filosóficas

\begin{tabular}{|c|c|c|c|c|}
\hline $\begin{array}{l}\text { MODOS DE SER } \\
\text { DIMENSIONES }\end{array}$ & MÍTICO & SISTEMÁTICO & PRAGMÁTICO & RELACIONAL \\
\hline PRAXEOLOGÍA & $\begin{array}{l}\text { Pasar el tiempo } \\
\text { juntos, comuniones } \\
\text { de los miembros, } \\
\text { Fiestas, ritos, } \\
\text { comidas, utilización } \\
\text { de palabras y de } \\
\text { símbolos, } \\
\text { realizar proezas y } \\
\text { acciones brillantes }\end{array}$ & $\begin{array}{l}\text { Tomar posición y } \\
\text { defenderla, proponer } \\
\text { normas y reglas } \\
\text { impersonales de } \\
\text { planes y } \\
\text { procedimientos, } \\
\text { producir documentos } \\
\text { escritos }\end{array}$ & $\begin{array}{l}\text { Encontrar soluciones } \\
\text { a los problemas } \\
\text { concretos, el } \\
\text { mejoramiento y la } \\
\text { innovación, el hacer } \\
\text { avanzar proyectos, } \\
\text { las realizaciones y las } \\
\text { obras, el desarrollo } \\
\text { de herramientas y de } \\
\text { técnicas }\end{array}$ & $\begin{array}{l}\text { Estar atento del } \\
\text { otro, escuchar, } \\
\text { formular preguntas, } \\
\text { dialogar, concertar y } \\
\text { negociar, llegar a } \\
\text { acuerdos, la cortesía } \\
\text { y la diplomacia }\end{array}$ \\
\hline EPISTEMOLOGÍA & $\begin{array}{l}\text { Memoria y tradición, } \\
\text { origen y filiación, } \\
\text { imitación y } \\
\text { repetición, } \\
\text { imágenes y alegorías, } \\
\text { intuición y olfato }\end{array}$ & $\begin{array}{l}\text { Registrar, clasificar, } \\
\text { abstraer, formalizar, } \\
\text { deducir, generalizar, } \\
\text { demostrar } \\
\text { lógicamente, buscar } \\
\text { las causas, el espíritu } \\
\text { de análisis y } \\
\text { geometría }\end{array}$ & $\begin{array}{l}\text { Explorar, observar, } \\
\text { proceder por ensayo } \\
\text { y error, formular } \\
\text { hipótesis, } \\
\text { experimentar, } \\
\text { verificar, modelar y el } \\
\text { espíritu de } \\
\text { descubrimiento }\end{array}$ & $\begin{array}{l}\text { La observación } \\
\text { participante, el } \\
\text { comprender, } \\
\text { interpretar, dar } \\
\text { sentido, } \\
\text { contextualizar, la } \\
\text { síntesis, la empatía y } \\
\text { el juicio }\end{array}$ \\
\hline
\end{tabular}

Fuente: Bédard (1995, 2000, 2002), Chanlat (1995) 
EI Modo de Ser mítico. El término es consagrado por Bédard (1995, 2002), para designar una forma de ser que difiere profundamente del pensamiento racional (la oposición mûthos / lógos). El Modo de Ser mítico representa una forma de comportamiento que se basa en el Uno. Son elementos claves de esta manera de ser, la unidad, entendida como un todo orgánico en la cual las partes están unidas por carácteres comunes y por su contribución al funcionamiento del conjunto; la unión como modo de relación dinámica, la comunión, la comunidad, la participación de la parte en el todo. El Modo de Ser mítico privilegia valores comunitarios como el espíritu de grupo, la noción de familia o de clan, el compartir, la solidaridad, la fidelidad, la filiación, el respeto de los valores tradicionales. Las actividades de palabra, las fiestas, las ceremonias, las comidas en común, las reuniones y los rituales, ocupan un lugar importante.

Esta manera de ser se encuentra en las organizaciones y los servicios que han adoptado una representación y modos de funcionamiento donde dominan el espíritu familiar y una solidaridad de tipo orgánico, como por ejemplo, en la cultura interna de los sindicatos, de las cooperativas, en las pequeñas y medianas empresas que tienen una concepción familiar, en las organizaciones sin ánimo de lucro; en los movimientos religiosos, ideológicos o clandestinos; en las municipalidades cuando el alcalde y su equipo se comportan como pater familias, etc..

Al interior de una organización, según Bédard (1995, 2002), este Modo de Ser se adapta bien a las unidades donde la función simbólica juega un papel importante, como por ejemplo, la Corte Suprema de Justicia y las fuerzas de seguridad; también donde lo sagrado, lo misterioso y lo poderoso se imponen como trasfondo de las circunstancias; igualmente, en las situaciones donde los valores y la caballerosidad son estimadas, es decir, el honor, el coraje, la bravura, la generosidad, la dedicación, la fidelidad, la lealtad, la cortesía y la protección de los débiles. Si la figura del héroe, del jefe de tribu o de clan, del padre de familia, o del maestro de la casa, son arquetipos del estilo de conducta que conviene a este modo de Modo de Ser, por el contrario, el integrismo, el absolutismo, el carismatismo y el clientelismo figuran entre sus patologías. En los últimos años hemos asistido a una rehabilitación en las empresas de este Modo de Ser, en particular con los estudios que tratan sobre la cultura organizacional.

EI Modo de Ser sistemático. Se trata del Modo de Ser más fácil de reconocer, dado que es muy frecuente, bien conocido y bastante documentado. Según Bédard (1995), a menudo se le designa en el lenguaje corriente como "el espíritu de sistema". Literalmente, el espíritu de sistema-que no debe confundirse con el Modo de Ser sistemático- evoca la idea general de una actitud más sensible a las construcciones intelectuales y teóricas que a los hechos, un espíritu que tiende a las construcciones racionales, a las teorías globales, a las construcciones totales susceptibles de informar del conjunto de los fenómenos, que tiene el gusto de la coherencia y de la elaboración. Los adjetivos de mayor uso que lo caracterizan son metódicos, ordenados, coherentes, racionales, cartesianos, lógicos y teóricos.

Según Bédard (1995, 2002), la personalidad que encarna la manera de ser sistemática corresponde al tipo weberiano racional - legal. Dicha personalidad se caracteriza por un gusto por el orden, la jerarquía, la clasificación, la preocupación por la perfección y la búsqueda de arquitecturas impecables. También, por proceder a partir de principios absolutos, de ideales de perfección, por apreciar los planes y las estructuras, la inteligencia formal, el espíritu de geometría. El Modo de Ser sistemático es dicotómico y se articula alrededor de categorías aristotélicas (la calidad, la cantidad, el lugar, el tiempo, etc.). El comportamiento sistemático da preferencia a la abstracción, a la generalidad y al concepto; es analítico, lógico y taxonómico. En sus excesos patológicos presenta los rastros negativos del legalismo, del autoritarismo, del dogmatismo, de la burocracia y de la tecnocracia.

El Modo de Ser pragmático. Como lo afirma Bédard (1995), "el espíritu pragmático", que aparece en el Renacimiento, presenta una orientación general utilitarista. Por ello, se entiende una actitud que da prioridad a los resultados, a la eficacia de la acción, a la experimentación, a la innovación y al mejoramiento continuo. El criterio último es que las cosas "funcionen". Las calidades que caracterizan la personalidad pragmática son el sentido de lo concreto, de las preocupaciones utilitarias, el espíritu innovador y la inteligencia 
práctica. En las organizaciones actuales, el modo de gestión y de funcionamiento por proyectos representa bien este comportamiento, que se adapta $\sin$ mayores dificultades a las organizaciones y departamentos cuya razón de ser está centrada en la resolución de problemas concretos, como los suministros, la logística, la gestión de los inmuebles, el transporte público, los trabajos públicos, etc. El utilitarismo, el oportunismo y el arribismo representan, de alguna manera, algunos de los peligros patológicos del Modo de Ser pragmático.

EI Modo de Ser relacional. Este Modo de Ser se hace cada vez más necesario, en la medida que el individuo concreto reivindica un status de sujeto pleno y que se emancipa de los grupos a los cuales pertenece. Llegar a entenderse sobre un sentido compartido sólo es posible si todas las partes en presencia hacen el esfuerzo de comprender el contexto de sus interlocutores y de aquellos con los cuales se presentan dificultades para entrar en relación. Los mediadores, los negociadores, los conciliadores de conflictos, los dirigentes que se perciben como animadores, encarnan la manera de ser relacional; son personas capaces de aceptar vivir en un mundo donde la verdad es relativa. Para tener éxito en este Modo de Ser, se requiere tener un franco espíritu de finura y delicadeza en las relaciones interpersonales.

Según Bédard (2002), el Modo de Ser relacional es particularmente recomendado en las organizaciones donde prevalece el igualitarismo, como por ejemplo, en la esfera política de la organización municipal, en los departamentos que pertenecen al tipo de la burocracia profesional, en los situaciones donde el personal de la función productiva es ampliamente autónomo, donde la diversidad de las personas es considerada esencial (juntas directivas, comités de trabajo), en las organizaciones focalizadas sobre el servicio a la clientela, en los medios donde la diplomacia prevalece sobre la jerarquía, en los momentos de conflictos de trabajo, en las situaciones donde los empleados y cuadros profesionales se consideran en igualdad de condiciones, en los casos cada vez más frecuentes que se pide a las personas ser creativas, entusiastas y brindar artículos de calidad. En síntesis, todas las formas de organización de tipo adocrático cuyo funcionamiento se base en ajustes mutuos, requieren para ser exitosas, la presencia del espíritu de conciliación y de concertación. En sus excesos patológicos, este Modo de Ser puede engendrar el individualismo, el regateo, el chanchullo, el igualitarismo aritmético.

En las investigaciones dirigidas por el autor en los últimos años ${ }^{2}$, una vez realizado el análisis de los Modos de Ser de los dirigentes, siguiendo el esquema que acabamos de plasmar, se observó que una cantidad importante de datos recopilados durante el "séjour d'observation participante", no pudieron ser utilizados para sustentar los cuatro modos de ser propuestos por Bédard (1995, 2002). La naturaleza aparentemente "rara" de tales hechos, caracterizados por la presencia de fenómenos tales como la resistencia, la impasibilidad, la ironía, el humor, la maldad, la hostilidad, el escepticismo, el sarcasmo, el escándalo, el irrespeto, la risa, la broma, la burla, entre otros, condujeron a indagar sobre estas categorías en las escuelas de la filosofía, encontrando respuesta en el cinismo, la más controvertida de las escuelas del pensamiento antiguo, y una de las que más avatares ha conocido en la historia del pensamiento occidental. En consecuencia, en la presente ponencia se documenta una reflexión sobre la presencia del cinismo en los dirigentes estudiados en las investigaciones mencionadas. ¿Se trata de un modo de pensamiento? ¿Son comportamientos patológicos de los modos de ser? Creo que las investigaciones y reflexiones contribuirán al debate sobre el tema. Por ahora lo presentaré, simplemente, como un comportamiento humano que admite ser estudiado desde las cuatro dimensiones filosóficas propuestas en el "rombo" filosófico de Renée Bédard (1995, 2000), es decir, estamos ante la presencia de un quinto Modo de Ser de los dirigentes.

Presentaremos aspectos sobre el cinismo encontrado las investigaciones: Sobre las relaciones Administración - Sindicato en Ecopetrol (ver Zapata 2007) y sobre Pensamiento estratégico y Modos de ser de los dirigentes (ver Reyes \& Ospina, 2007). 


\section{InTRoducción aL Cinismo}

Le cynisme est "ce qui peut être atteint de plus haut sur la terre ; il faut, pour le conquérir, les poings les plus hardis et les doigts les plus délicats"

(Nietzsche, Ecce Homo)

Encuentro de tercer tipo

Administración: Limpieza de pozos es actividad petrolera no permanente.

Sindicato: Un vivero no es de la industria del petróleo ? ...(risas) ... Es el colmo que no sea... (risas) ...

Administración: Casinos, cafetería y aseo no son de la industria del petróleo, vigilancia no está dentro de la definición, mantenimiento de vías tampoco.

Sindicato: $\quad$ Se están pasando de calidad (vivos), nos están diciendo muchas mentiras.

Administración: Lo único que es posible discutir es lo de mantenimiento de pozos e instrumentación. Estamos trabajando con la filosofía del costo.

Sindicato: "La Administración dijo que la reversión de la Concesión de la Exxon de Sabana de Torres no es de la industria del Petróleo", así iniciaremos la presentación nuestra en la próxima asamblea de trabajadores.

Cynique. Se dit de philosophes anciens (comme Diogène) qui professaient une morale ascétique et un dédain absolu des convenances sociales. Impudent, inconvenant : langage cynique. (Petit Larousse)

Cynisme. Emprunté au latin de basse époque cynismus et dérivé du grec Kuôn, Kunos, il sert de nom abstrait à "qui appartient à l'école cynique" et "qui concerne le chien". Doctrine des philosophes cyniques. Mépris des convenances, de la morale, qui se traduit par une impudence effrontée : un cynisme révoltant. (Petit Larousse, Universalis)

El cinismo surgió en el siglo V a.c., con Anthisthème (445-360), uno de los intérpretes más intransigentes de Sócrates, cuyas ideas, propagadas más tarde por Diogènes de Sinope (alrededor de 404-323), suscitarían durante más de diez siglos múltiples vocaciones de filósofos cínicos (Jouary et Spire, 1997).

En los años 1980, un debate importante se desarrolla en Alemania sobre el cinismo. Preocupada por distinguir la nueva ocurrencia del concepto, la lengua alemana utiliza dos términos distintos: Kynismus para el cinismo antiguo, y Zynismus para su sentido contemporáneo. Dos obras han analizado el cambio de sentido del concepto de cinismo: en 1979, Heinrich Niehues-Pröbsting publica Le cynisme de Diogène et le concept de cynisme y cuatro años más tarde, Peter Sloterdijk entrega al público su Critique de la raison cynique (Jouary et Spire, 1997).
En los años 1990, por su parte, es Francia la que participa del debate con la obra de Jean-Paul Jouary et Arnaud Spire (997), Servitudes et grandeurs du cynisme. Para estos autores, el cinismo expresa el rechazo de que lo real y lo ideal pudiesen a la vez contradecirse y unirse (Jouary et Spire, 1997).

\footnotetext{
"La esencia del cinismo en el siglo 20 podría esquematizarse de la siguiente manera: En primer lugar, yo sé las diferencias; en segundo lugar, todo es equivalente; en tercer lugar, no hago nada porque estoy seguro de antemano que nada sirve para nada ; en cuarto lugar, propago la desmoralización alrededor de mi, incitando mis enemigos a actuar. En cuanto a mis amigos me encargo de neutralizarlos" (Jouary et Spire, 1989: 154).
}

En el plano ideológico, el cinismo es una especie de disfuncionamiento de la actividad humana que integra durablemente la disociación entre valores 
y comportamientos (Jouary et Spire, 1997). Sloterdijk (1987), en su profundo estudio sobre la razón cínica, la define como la falsa conciencia ilustrada y señala seis grandes campos donde el valor no cesa de oponerse a la verdad: el ejército, la política, la sexualidad, la medicina, la religión y el saber. Me pregunto: ¿Es que el campo de la gestión está en camino de convertirse en el séptimo? Algunas referencias indican que, desafortunadamente, se avanza en ese sentido. Alain Chanlat y Renée Bédard (1990) mostraban que en numerosas circunstancias, las figuras de autoridad encuentran razones para incumplir la palabra empeñada.

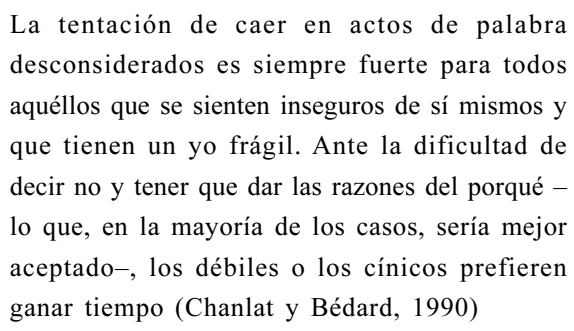

Lo cual coincide con la posición cínica que pone de manifiesto la falsa seriedad y los simulacros de comunicación social. Ricardo Matamala, en su libro "La perversidad en las organizaciones", denuncia que "el cinismo y la facilidad para ser incongruente y acomodar la realidad a la conveniencia, es común en personas con ansias de poder, que anteponen sus deseos e intenciones al bien común".

En el plano filosófico se trata de una especie de renuncia a todo esfuerzo de alcanzar la coherencia entre el pensamiento, la palabra y la acción. No se trata de decir lo que pensamos, y aún menos de hacer lo que decimos (Jouary et Spire, 1997). Desde la perspectiva psicoanalítica, el cinismo se trata de un mecanismo de defensa. El cinismo no es nada menos que una forma de pensamiento que integra su no-sistematización (Jouary et Spire, 1997).

Las calidades maestras del cinismo son: la resistencia (l'endurance). El dominio de sí mismo (la maîtrise de soi). La impasibilidad (l'impassibilité). La ironía (l'ironie), el cinismo toma la ironía socrática, hecha de medida y sentido crítico. El humor (l'humour). La maldad (le méchant). La hostilidad (l'hostilité). La amenaza permanente de la Administración de convocar el Tribunal de Arbitramento y la respuesta inmediata y tajante del Sindicato de hacer la huelga "antes que tribunal huelga general". Amenaza contra amenaza. Hostilidad contra hostilidad. No futuro (no future). "El cinismo contemporáneo ha tomado los pasos de una especie de bon sens. Su tendencia a encerrar el futuro en mediocres escenarios Fuente : Bédard $(1995,2000,2002)$, Chanlat (1995) revisibles y sin envergadura se convierte progresivamente en una de las cosas más compartidas en el mundo. No future..." (Jouary et Spire, 1997). El escepticismo (le scepticisme), para el cinismo nada está determinado y nada es racional. El sarcasmo (le sarcasme), para el cinismo la convención llama al irrespeto. El escándalo (le scandale), para el cinismo los principios existen para ser enfrentados. $\mathrm{El}$ irrespeto (l'irrespect). La risa (le rire). La broma (la dérison). La burla (se moquer). El espíritu díalético (l'esprit díalectique). La provocación. El dogmatismo artificial, el cínico se aferra al radicalismo epistemológico artificial.

La Tabla siguiente presenta las categorías maestras del cinismo de acuerdo a las dimensiones filosóficas del "rombo" propuesto por Bédard (1995, 2000)

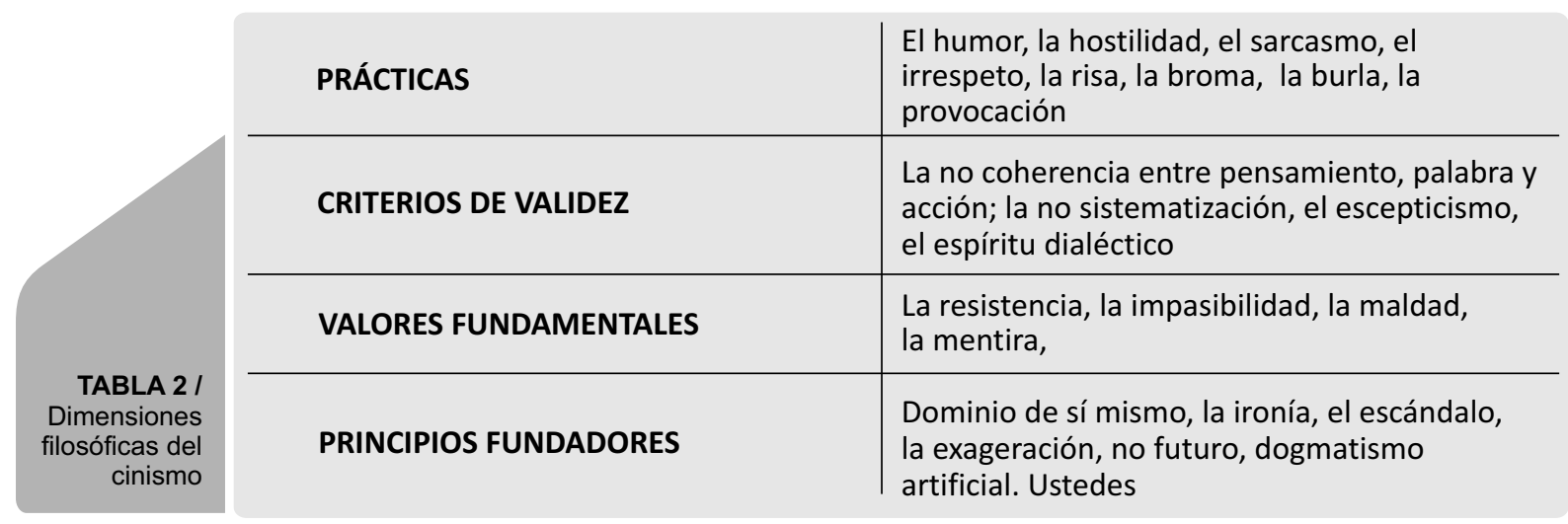


Hay varias maneras de aprehender el cinismo de los dirigentes; la más elemental consiste en colocar en evidencia su significación estratégica, política en general, y analizar las formas de su realidad social que hacen el cinismo posible y necesario.

\section{EL MODO DE SER CÍNICO}

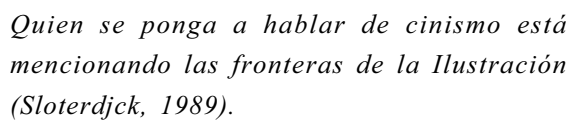

Reconocemos al cínico vulgar en algún momento, ya sea como un auto reflejo, o con la insolente mirada al "otro". El cínico se reconoce y se hace cínico en el mismo momento que el "otro", le sigue su juego o simplemente, como en un espejo: tan solo es su auto-reflejo. ¿Quién no ha dicho entre risas su pensamiento para disfrazar un poco la verdad con el único interés de no ofender directamente?; ¿Quién no ha incorporado la ironía socrática como parte del humor? Estos aspectos del cinismo permiten ver a los dirigentes desde una mirada diferente: "Desde el modo de ser", lo más humana o inhumana posible y no como "robots" que siguen un modelo ó un manual.

No siendo la propuesta cínica una doctrina, sino una manera de vivir, pertenece a la categoría del dejar-se el individuo y, al nivel del pensamiento, a un nivel de liberación de éste respecto de las ataduras dogmáticas que 10 mantienen encadenado. Lo crucial del cinismo y de su respectiva interpretación, es el re-pensar de una manera distinta la filosofía. Pero ese "vivenciar" cínico, no puede ser entendido como una especie de placidez en el desarrollo de la cotidianidad, ni como el simple experimentar con la vida "práctica". Tal 'vivenciar' tiene que ver con la manera como el pensamiento inmediatiza lo vivido, se apropia de ello, apropiación en la cual el pensamiento no es algo exterior a lo que vive, sino que se hace uno con él. Por ello, las deducciones lógicodeductivas no cuentan para el cínico, no son su 'verdad'; el cínico acude a la realidad no deduciendo, sino demostrando, lejos de toda premisa moral, acogiéndose únicamente a la naturaleza de las cosas.

A propósito de la pregunta si el cinismo es o no filosofía, es sintomático saber que existía, por parte de los cínicos antiguos, un rechazo a toda noción de cultura intelectual pues la juzgaban inútil, pues se apartaban de aquello que verdaderamente debían tematizar, al hombre mismo contra todo saber teórico, contra todo pensamiento lógicodeductivo, el cínico proponía una filosofía de la improvisación y del acto.

Hoy en día, se ha tomado la palabra 'cínico' como un término peyorativo para señalar a alguien cuya manera de ser es despreciable, y no como un pensamiento (o una postura) filosófica.

La actualidad del cinismo evidentemente se mueve en múltiples direcciones, siendo una de las más destacables el cuestionamiento del rol que desempeña la filosofía en el universo del pensamiento y del discurso humano.

Las prácticas que caracterizan el cinismo, como son: el humor, la hostilidad, el sarcasmo, el irrespeto, la risa, la broma, la burla, la provocación, se pudieron observar en situaciones diversas. El pensamiento cínico se expresa a nivel de la acción cuando una de las partes ridiculiza la posición de la otra. El cinismo de quien dirigía una campaña de valores, en una de las empresas estudiadas, la cual tuvo que suspenderse cuando la dirección se percató que quien la dirigía no practicaba uno de los valores fundamentales de la misma. Hablar de respeto, tema de la campaña, cuando no respetaba ni siquiera a sus inmediatos colaboradores.

\section{El LÍDER TIENE QUE SER INDIVIDUALISTA}

El cínico no propone dentro de sus proyectos, ideales colectivos o sociales, su liberación es concebida como un desafío enteramente individual, pues así como su objetivo era no depender del mundo de las necesidades creadas (por la 'civilización'), tampoco quería depender de los demás individuos, pues, para el cínico, lo único concreto es lo singular. Así que la expresión más particular de la individualidad cínica es la autosuficiencia. Con esto, los cínicos niegan la posibilidad de un conocimiento y de una transformación colectiva, por lo que lo único transformable es el individuo como tal Reyes, (2003).

El dirigente cínico se declara autosuficiente desde su primera etapa de crecimiento cuando no acepta haber recibido ningún aporte familiar o cultural a su capacidad 'cognitiva' de reconocer la oportunidad de negocio, o más aún esa 'vena 
empresarial' que lo impulsó a crear empresa y que lo puede hacer diferente a sus congéneres. Lo anterior, lo expresa Reyes (2003), cuando reconoce que lo que no pertenece, en verdad, al hombre, son sus parientes, domésticos, amigos, reputación, lugares familiares, relaciones sociales, etc.

Los criterios de validez propios del cinismo, como son : la no coherencia entre pensamiento, palabra y acción; la no sistematización, el escepticismo, el espíritu dialéctico, se pudieron observar cuando, por ejemplo, un sindicato dice que "en muchas ocasiones hemos expresado que queremos negociar bajo parámetros de orden, de paz, de convivencia, etc.", la realidad es que las prácticas observadas, que ellos mismos reconocen indican que "nuestras negociaciones a través del tiempo, han sido marcadas por la violencia y el tratamiento de guerra contra nuestra organización sindical y por la especulación contra nuestras peticiones". Existe pensamiento cínico cuando una demanda, solicitud o posición, propia del nivel de la soberanía, se presenta como una demanda del nivel económico, utilizando criterios de validez del modo de Modo de Ser sistemático. La invitación permanente al diálogo se convierte en un diálogo estéril, un diálogo de sordos, particularmente cuando se trata de demandas relacionadas con el nivel de la soberanía y gobernabilidad. De antemano el cínico dice "No. Pero dialoguemos".

Los principios fundadores que identifican el cinismo, son: el dominio de sí mismo, la ironía, el escándalo, la exageración, el no futuro, el dogmatismo artificial, aparecen de diversas maneras.

El cínico reclama la realidad del aquí y del ahora, por ello, no cree en la posibilidad de ir más allá del hombre mismo. Para el cínico la realidad no puede ser comprendida como una búsqueda de justificación del mundo en un más allá.

Al respecto Onfray (2005), expresa: "Dada la instantaneidad de cada acto, todo lo que se hace es éticamente conforme desde el instante que yo lo hago, en función de la situación presente, que demanda cierto tipo de proceder. Así, la instantaneidad del discurso, corresponde a la instantaneidad del comportamiento".
También Reyes (2003), afirma que la realidad del hombre consiste en el desempeño que él mismo logra, y su única enseñanza no le proviene de un esquema, sino de todo aquello que aprehende de la vida misma. Sin ser un funcionalismo, los cínicos sí evitaron acudir a la teoría, en sentido platónico. El cínico rechaza desde todo punto de vista, la conceptualización, la intención de convertir lo existente en concepto. Se trata de refutar lo que se concibe sobre lo que se percibe. El decir de los cínicos no es solamente decir una verdad, es indicar una realidad. Así pues, el razonamiento cínico está más guiado por la argumentación de la cotidianidad y por la intuición que por la estructura lógicosemántica que se sobrepone a la realidad. Y como lo expresa Onfrey (2005), el razonamiento cínico está más guiado por la argumentación de la cotidianidad, que por la estructura lógicosemántica. Los dirigentes cínicos parecieran conocer de primera mano toda la explicación.

A diferencia de Sócrates, que concedía gran importancia a lo social y al intelecto, los cínicos encuentran la virtud en lo individual y en lo no intelectual. Por eso es que no elaboran una doctrina moral sistemática sino que se constituyen ellos mismos en testimonio de la virtud, la cual no es un saber sino un modo de vida ascética, de abstinencia y autodominio.

El cínico es el filósofo de la situación límite, de lo azaroso de la existencia. La vida no necesita ser fundamentada por fuera de sí misma, dicho de otra manera, resulta absurdo construir un "modelo" teórico para posteriormente 'aplicarlo' a una realidad. La realidad del hombre consiste en el desempeño que él mismo logra, y su única enseñanza no le proviene de un esquema, sino de todo aquello que aprehende de la vida misma. Sin ser un funcionalismo, los cínicos sí evitan acudir a la teoría, en sentido platónico.

Como lo evidencia claramente Savater en la Crítica a la razón cínica: El hombre socializado es aquel que ha perdido su libertad desde el momento en que sus educadores han logrado plantar en él deseos, proyectos, ambiciones. Estos le separan de su época interior, que sólo conoce el ahora, y le llevan a expectativas y recuerdos Savater, (1998). El sabio pone de manifiesto que literalmente puede vivir en todas partes, dado que él, en cualquier lugar, coincide consigo mismo y con "las leyes de la naturaleza". 
Los valores fundamentales que distinguen el cinismo, como son: la resistencia, la impasibilidad, la maldad, se encontraron en aspectos como los que se comentan a continuación. Hay cinismo cuando se acepta un acuerdo sobre algo que no requiere negociación, pues de trata de algo existente, en construcción o desarrollo, o que la empresa está realizando mutuo propio". El dirigente cínico muestra indiferencia (impasibilidad) ante los problemas de sus empleados.

\section{El Perro Sabueso}

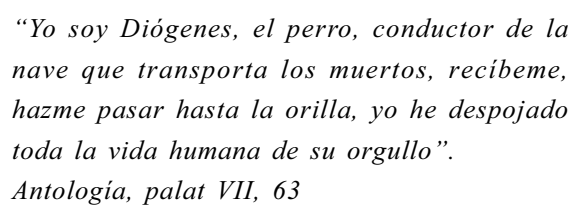

El cínico se enorgullece de imitar a los perros más audaces y más incisivos. Evolucionando en el bestiario de la Fontaine, Diógenes sería pariente del lobo que fustiga al perro por obtener su pitanza cotidiana pagando el alto precio de su libertad y su autonomía Onfray, (2005).

Independientemente de que el dirigente cínico sea un perro sabueso, lo cierto es que no vive protegido junto a su patrón; por el contrario, él busca su propia autonomía y su autosuficiencia.

Antístenes, a quien se considera el padre fundador de la escuela cínica, fue llamado "el Verdadero Can" por Diógenes Laercio, VI. 54. La etimología (procedencia) confirmará el parentesco del animal y la escuela (cynós: "perro" en griego), y en el concepto podrá hallarse un misterioso perro brincando bajo el sol y las estrellas de Atenas. A Semejanza del perro el dirigente cínico expresa: “... Lo que pasa es que todo es 'olfato' hasta que se convierte en base de datos e historia. Entonces ya puede haber estadística...."

A los cínicos antiguos les gustaba llamarse perros sencillamente porque sentían una particular inclinación por las virtudes del animal. No es este perro el faldero dócil, sumiso y satisfecho, que vive protegido junto a sus amos tan ahítos como él; por el contrario, el cínico desconoce la correa, la casilla y la pitanza regular adquirida al precio del conformismo.
El dirigente cínico, además de llamarse perro, tiene la certeza de que se trata de un 'Perro Sabueso', haciendo un símil con los diálogos de Diógenes, podemos ver la aproximación con la respuesta a la pregunta: "Qué clase de perro eres tú? - le preguntaron a Diógenes-. Cuando tengo hambre - respondió- soy un Maltés, y saciado, soy un Moloso: dos razas que la mayor parte de la gente elogia, pero que pocos se animan a seguir en la caza por temor al esfuerzo" (Diógenes según Onfray, 2005). De modo que, para los lugares comunes y las mitologías seculares, se trataba de un 'sabueso'.

Diógenes optaba por la invectiva o el insulto. Así, a los curiosos que lo trataban de perro por sus prácticas alimentarias exhibicionistas, les contestaba: "Vosotros os parecéis más a los perros, puesto que me rodeáis mientras cómo". Onfray, (2005).

Los principios fundadores que identifican el cinismo, cono son: El dominio de sí mismo, la ironía, el escándalo, la exageración, no futuro, el dogmatismo artificial, aparecen de diversas maneras. El Modo de Ser mítico del sindicato al discutir temas relacionados con la soberanía eleva el nivel de la confrontación. Pero al mismo tiempo, conlleva a que sean dejados de lado, muchos aspectos importantes del nivel económico, como los salarios por ejemplo, recordemos cómo se negocian al final, en el último momento, con desdén, ironía, cinismo. Poco importa el monto, vale el show. El pensamiento cínico combina la zanahoria con el garrote. Garrote ideológico contra los dirigentes sindicales y contra los mandos medios de la empresa. Las zanahorias son de varias clases. Un falso status a ciertos cargos para comprarle la conciencia a las personas que los ocupan. Programas de méritos no merecidos y becas para líderes sindicales, El cinismo Neoliberal. Hay pensamiento cínico cuando se exagera una realidad, para llamar la atención o para pretender un comportamiento o una respuesta de un interlocutor o de una contraparte, cuando se tiene una relación o una negociación con él. El dogmatismo artificial, punto culminante de cinismo (Jouary et Spire), se expresa nítidamente en los dirigentes de la empresa, cuando ofician como voceros del gobierno. La Administración se inspira en la doctrina neoliberal, ideario adoptado por los gobiernos colombianos desde finales de la década de los años 1980. Esta orientación filosófica se refleja en la concepción 
que la Administración tiene sobre diferentes aspectos relacionados con la gestión general de la empresa y de las relaciones laborales en particular.

\section{TOdo ES UNA REACCIÓN QUímICA... ESE ES MI} PRINCIPIO

Finalmente, el cínico posee del perro, la virtud de la fidelidad y la preocupación por preservar y cuidar a su prójimo. Un día que Diógenes insistía en que lo llamaran perro, Polixeno, el dialéctico, se sintió incómodo y le comunicó su perturbación al sabio, quien lo tranquilizó diciéndole: "Tu también llámame perro; Diógenes, para mí, no es más que un sobrenombre; soy, en efecto, un perro, pero me cuento entre los perros de raza, los que velan por sus amigos" (Gnomologium Vaticanum, 194. Citado por Onfrey, 2005). El filósofo practicaba la mordedura con fines pedagógicos: a través de ella procuraba inculcar más sabiduría y virtud. "Los demás perros -afirmaba- muerden a sus enemigos, mientras que yo muerdo a mis amigos con la intención de salvarlos". (Estobeo, Florilegio, M 3.27 , citado por Onfrey, 2005).

La pareja formada por el perro y su amo también sirve para expresar la amistad, que Diógenes definía como la relación que permite que "una sola alma repose en dos cuerpos" (Damasio, Florilegium, I. 10. 10 - según Onfrey, 2005). Ladrar y morder son modos de llamar la atención sobre la dirección que conviene seguir, de mostrar el camino que hay que recorrer.

Es aquí como el dirigente cínico siente total confianza, esa que inspira un perro maltes a su amo que está seguro que su cachorro daría la vida por él. Está indiscutiblemente seguro y sabe qué puede esperar de un empleado suyo, quien daría la vida por él.

Otro de los rasgos que caracterizan al perro es su manía de ladrar a lo que desconoce. Así deberíamos interpretar a Heráclito (Fragmentos 97, según Onfray, 2005) cuando dice: "Los perros ladran contra todo lo que no conocen”. El cínico gruñe ante todo lo que contradice su ideal de virtud: cualquier cosa que se oponga a la autonomía y la independencia. Platón describe esta extraña manía - fidelidad al semejante, redoblada por la constancia- como el signo distintivo del guardián de la ciudad:

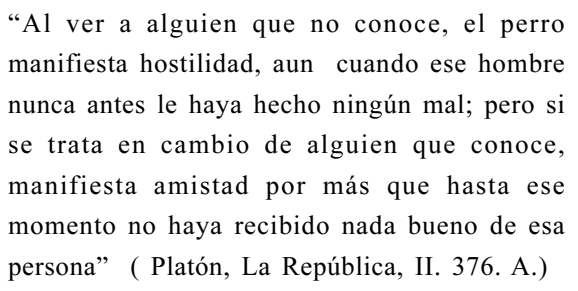

Así, las alianzas con otras empresas pueden ser algunas de las estrategias que convienen al dirigente cínico para penetrar con mayor eficacia en el mercado, y estas como todas las decisiones del dirigente cínico, dependen de su 'intuición', de su 'reacción química'.

Utilizando de una manera figurativa, el término sarnoso, errante e íntimo de las estrellas, el cínico husmea las sendas que conducen a la virtud (Onfray, 2005).

\section{SI ALGÚN díA Yo TENGO QUE ESCOGER... SE TIENEN QUE IR LOS DOS}

El cínico no sólo pertenece al cosmos, (entendido en su acepción general de 'orden'), sino que también está referido al kaos; el des-orden es su cotidianidad, él no concilia con nada ni con nadie, no trata de perfeccionar una realidad, pues ésta sólo toma cuerpo en cuanto es necesaria para su existencia. El orden pertenece al sentido de cómo debe ser una realidad; mientras que el kaos es el sentido del dejar-ser una realidad, no la realidad del sistema, sino la realidad enteramente individual.

Es así como el dirigente cínico, no desea transmitir ningún tipo de mensaje a sus empleados, ni mostrar afinidad hacia 'otro', como tampoco quisiera entrar a justificar su actuar, ni mucho menos pensar con respecto a las diferencias generadas entre las personas. Es como si ratificara que todos compartimos en des-iguales grados el saber y el comportamiento, teniendo derecho a ejercerlo libremente.

Los cínicos son atemporales y, por consiguiente, de una candente actualidad. La mejor manera de perdurar consiste en no pertenecer a ninguna 
época, pues de ese modo todo tiempo es el tiempo de uno. Indiscutiblemente, Diógenes podría encontrar su lugar en los albores del siglo XXI. Que no esté presente no significa que no haga falta, como manifiesta el dicho popular.
Seguramente el dirigente cínico se asumirá como cínico desde la acepción clásica por ir en contra de la corrupción y denunciar valeroso los vicios y costumbres de los corruptos partidos políticos. Señala y con los otros dedos se apunta a sí mismo. El dirigente cínico acusa desde un pedestal francamente débil.

\section{REFERENCIAS BibLIOGRÁFICAS}

Bédard, R.(1995). Les fondements philosophiques de la direction, Montréal, HEC, Thèse de Doctorat en Administration.

Bédard, R.(2000). "Les fondements de la pensée et de la pratique administratives: Le losange aux quatre dimensions philosophiques et La trilogie administrative. HEC-Montréal, Groupe Humanisme et Gestion. (manuscrito inédito)

Bédard, R.(2002). "Los cuatro Modos de Ser: teoría y aplicaciones a la gestión”. HEC-Montréal, Groupe Humanisme et Gestion, (manuscrito inédito)

Chanlat, A. (1995) Modos de pensamiento y comunicación. HEC-Montréal, Groupe Humanisme et Gestion, (manuscrito inédito).

Chanlat, A. et Bédard, R.(1990) "La gestion, une affaire de parole", dans L'individu dans l'organisation. Les dimensions oubliées, Québec et Paris, Les Presses de l’Université Laval et Eska.

Jouary, J. et Spire, A. (1997). Servitudes et grandeurs du cynisme, Saint Laurent (Québec), FidesDesclée de Brouwer.

Onfray, M.(2005). Cinismo - Retrato de los filósofos llamados perros. Argentina.

Reyes, O. (2003). El desafío Cínico Ediciones desde abajo, Bogotá.

Savater, F. (1998) Presentación. En SLOTERDJK, Meter. Crítica de la razón cínica I. Altea, Taurus, Alfaguara, S.A. España.

Sloterdijk, P. (1987) Critique de la raison cynique, Paris, Christian Bourgois éditeur.

Zapata, A (2007). Negociación, conflicto, mitos y poder en la gestión de las relaciones laborales en Ecopetrol. Cali, Universidad del Valle - Facultad de Ciencias de la Administración 